\title{
Plant regeneration in Arachis stenosperma Krapov. and W. C. Gregory from roots and calluses derived from leaflets of in vitro plants
}

\author{
Georgia Pacheco • Rachel Fatima Gagliardi • \\ Leonardo Alves Carneiro • \\ José Francisco Montenegro Valls • Elisabeth Mansur
}

Received: 27 November 2006 / Accepted: 23 July 2007 / Published online: 3 October 2007 / Editor: N.A. Reichert

(C) The Society for In Vitro Biology 2007

\begin{abstract}
Seed explants of A. stenosperma were cultured on MS medium supplemented with 6-benzylaminopurine with the aim of rescuing nonviable accessions stored in seed bank conditions. The regeneration potential of leaf explants from in vitro plants derived from embryonic axes was studied by using whole leaflets and leaflet segments. Explants were cultured on Murashige and Skoog (MS) medium supplemented with different concentrations of 6-benzylaminopurine and naphthalene acetic acid. Indirect organogenesis was observed in response to 6-benzylaminopurine, either alone or in association with naphthalene acetic acid, in both explant types. Media supplemented with naphthalene acetic acid as the sole growth regulator induced rhizogenesis in whole leaflets and leaflet segments, with subsequent shoot production directly from the roots.
\end{abstract}

Keywords Groundnut - Micropropagation .

Organogenesis $\cdot$ Rhizogenesis

G. Pacheco • R. F. Gagliardi • L. A. Carneiro • E. Mansur Laboratório de Micropropagação e Transformação de Plantas, DBCG-Universidade do Estado do Rio de Janeiro,

Rio de Janeiro, Brazil

\section{J. F. M. Valls}

Embrapa Recursos Genéticos e Biotecnologia, Brasília, Brazil

E. Mansur $(\bowtie)$

Laboratório de Micropropagação e Transformação de Plantas, Universidade do Estado do Rio de Janeiro, IBRAG, DBCG, Rua São Francisco Xavier 524, PHLC sala 505, CEP 20550-013 Rio de Janeiro, RJ, Brazil

e-mail: elisabeth.mansur@gmail.com

\section{Introduction}

Arachis stenosperma Krapov and W. C. Gregory is a wild species of the genus Arachis (section Arachis), recognized as an important gene source for the genetic improvement of the groundnut (A. hypogaea L.) because of the close relationship between the two species. Among the desirable traits that can potentially be transferred to groundnut are the high lipid contents (Grosso et al. 2000) and resistance to many economically important diseases such as rust, groundnut rosette disease, and nematodes (Sharma et al. 1999; Subrahmanyam et al. 2001). A. stenosperma is endemic to Brazil and grows as an annual herb in the Atlantic Coast and in the State of Mato Grosso, in areas endangered by environmental erosion and human actions. Because of this, breeders and conservationists have expressed serious concerns with the sustainability of this species.

Arachis seeds are considered as sub-orthodox and must be periodically renewed when stored in seed banks. However, even under optimal conditions seeds may lose viability, impairing renewal and leading to losses of valuable germplasm (Dunbar et al. 1993). Therefore, in vitro preservation techniques, which are based on micropropagation procedures, are considered as an important method for recovery, multiplication, and distribution of wild species of this genus.

The regenerative capacity of seed explants of wild Arachis species is well-documented and several accessions have been rescued and multiplied through culture of embryo axes and cotyledons (Gagliardi et al. 2000; Pacheco et al. 2007). However, cotyledons often lose their regenerative potential, probably because of injuries during seed storage (Morris et al. 1995), limiting the number of plants that can be recovered from each genotype. Hence, the study 
of alternative explants for in vitro multiplication is relevant for in vitro conservation programs. Moreover, additional studies are still necessary to explore the in vitro morphogenic potential of wild Arachis species through direct regeneration pathways.

In this work, seed explants of $A$. stenosperma were used to rescue nonviable accessions stored in seed bank conditions. The regeneration potential of leaf explants was evaluated as an alternative method to achieve in vitro multiplication.

\section{Materials and Methods}

Plant material and culture conditions. Seeds of A. stenosperma (accessions V 9017, V 10229, V 12575, and V 14455) stored at $10^{\circ} \mathrm{C}$ and $25 \%$ relative humidity were provided by the Embrapa Genetic Resources and Biotechnology seed bank (Brasília, DF). The basal medium for all experiments consisted of MS salts and vitamins (Murashige and Skoog 1962) supplemented with $3 \%(w / v)$ sucrose and solidified with $0.7 \%(w / v)$ agar. The $\mathrm{pH}$ for all media was adjusted to 5.8 before autoclaving for $15 \mathrm{~min}$ at $121^{\circ} \mathrm{C}$. Cultures were maintained in a growth chamber at $28^{\circ} \mathrm{C} \pm 2^{\circ} \mathrm{C}$ with $16 \mathrm{~h}$ light $/ 8 \mathrm{~h}$ darkness and a total irradiance of $46 \mu \mathrm{M} \mathrm{m}^{-2} \mathrm{~s}^{-1}$ provided by cool-white fluorescent lamps.

Micropropagation. Seeds were disinfected by immersion in a $0.2 \%(w / v) \mathrm{HgCl}_{2}$ solution for 45 min under agitation. After surface sterilization, seeds were washed three times with sterile de-ionized water and peeled. Embryonic axes and cotyledons were then aseptically excised and transferred to culture vessels $(250 \mathrm{~mL})$ containing MS medium supplemented with 8.8 and $110 \mu \mathrm{M}$ 6-benzylaminopurine (BA), respectively (Gagliardi et al. 2000).

Leaflets were excised from in vitro plants derived from embryonic axes, 3 mo. after culture initiation. The influence of wounding on the regeneration efficiency was evaluated by using two types of explants: whole leaflets and leaflet segments $(1 \mathrm{~cm})$ cut in half perpendicular to the midrib, both cultured with the abaxial side down on the medium. Explants were cultured on Murashige and Skoog (MS) medium supplemented with different concentrations and associations of BA $(4.4,8.8,22,30.8$, and $44 \mu \mathrm{M})$ and naphthalene acetic acid (NAA) $(5.4,10.8,27,37.8$, and $54 \mu \mathrm{M})$. The developed shoots were subsequently transferred to MS medium without growth regulators (MS0) for elongation and rooting.

Data collection and statistical analysis. Regeneration frequencies and mean number of shoots produced per explant were recorded after 8 wk of culture, at 2 -wk intervals. Ten replicates were taken in each treatment and each experiment was repeated three times. Data were subjected to analysis of variance (ANOVA) and comparisons of means were carried out with Student-Newman-Keuls Multiple Comparisons Test at $0.05 \%$ significance level using the software GraphPad Instat.

\section{Results and Discussion}

Cotyledons from all accessions cultured on MS medium supplemented with $110 \mu \mathrm{M}$ BA showed high levels of oxidation and necrosis, and failed to regenerate. These results are in agreement with those obtained in other Arachis species (Pacheco et al. 2007) and may be attributed to oxidative injuries during seed collection or storage, which may result in metabolic abnormalities (Morris et al. 1995).

Embryonic axes from accessions V 14455 and V 12575 developed shoots after 2 wk of culture on MS supplemented with $8.8 \mu \mathrm{M}$ BA at frequencies of $76.7 \%$ and $40 \%$, respectively. Multiple shoot formation was not observed, in contrast to the behavior displayed by explants of other Arachis species cultured in the same conditions (Gagliardi et al. 2000). Explants from accessions V 10229 and V 9017
Table 1. Effect of different combinations of NAA and BA on shoot regeneration via indirect organogenesis from leaf explants of $A$. stenosperma after $8 \mathrm{wk}$ of culture

Values are means \pm standard error. Means followed by the same letter in a column were not statistically different by Student-Newman-Keuls Multiple Comparisons Test $p \leq 0.05$ level.

\begin{tabular}{|c|c|c|c|c|c|}
\hline \multicolumn{2}{|c|}{ Growth regulator } & \multicolumn{2}{|l|}{ Whole leaves } & \multicolumn{2}{|l|}{ Leaf segments } \\
\hline NAA & $\mathrm{BA}$ & Callogenesis $(\%)$ & Shoots/explant & Callogenesis (\%) & Shoots/explant \\
\hline 0 & 4.4 & 91.7 & $4.5 \pm 1.2 \mathrm{~b}$ & 100 & $2.3 \pm 0.6 \mathrm{ab}$ \\
\hline 0 & 8.8 & 83.3 & $4.6 \pm 1.2 \mathrm{~b}$ & 100 & $2.08 \pm 0.6 \mathrm{a}$ \\
\hline 0 & 22 & 91.7 & $4.8 \pm 1.3 \mathrm{~b}$ & 100 & $5.08 \pm 1.3 \mathrm{~b}$ \\
\hline 0 & 30.8 & 100 & $2.5 \pm 0.7 \mathrm{ab}$ & 100 & $1.62 \pm 1.0 \mathrm{a}$ \\
\hline 0 & 44 & 91.7 & $3.6 \pm 0.6 \mathrm{ab}$ & 100 & $2.42 \pm 0.5 \mathrm{ab}$ \\
\hline 5.4 & 4.4 & 100 & $3.2 \pm 1.4 \mathrm{ab}$ & 100 & $3.8 \pm 0.3 \mathrm{ab}$ \\
\hline 10.8 & 4.4 & 100 & $1.5 \pm 0.3 \mathrm{ab}$ & 100 & $2.25 \pm 0.6 \mathrm{ab}$ \\
\hline 27 & 4.4 & 100 & $0.5 \pm 0.2 \mathrm{a}$ & 100 & $0.87 \pm 0.4 \mathrm{a}$ \\
\hline 37.8 & 4.4 & 100 & $0.25 \pm 0.2 \mathrm{a}$ & 100 & $0.5 \pm 0.3 \mathrm{a}$ \\
\hline 54 & 4.4 & 100 & $0.125 \pm 0.1 \mathrm{a}$ & 100 & $0.125 \pm 0.1 \mathrm{a}$ \\
\hline
\end{tabular}




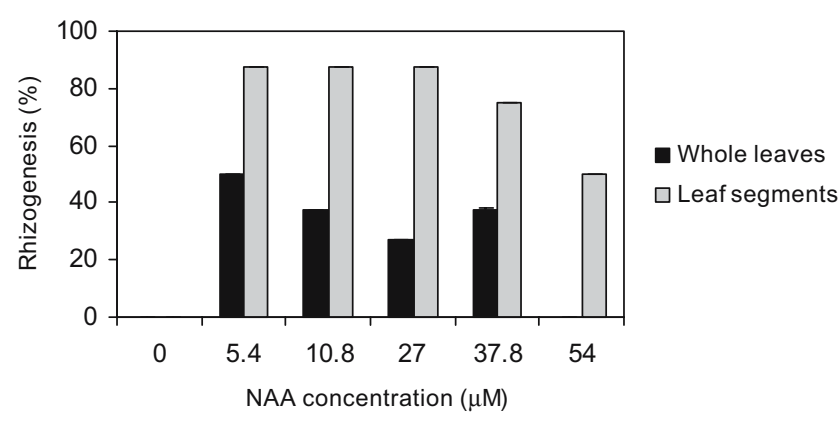

Figure 1. Rhizogenesis from leaf explants of A. stenosperma (V $14455)$ in response to different NAA concentrations, after $8 \mathrm{wk}$ of culture.

did not show regeneration in the same culture medium, after $60 \mathrm{~d}$ of culture. The differences among the responses of different accessions may be related to genotypic characteristics or to injuries, including auto-oxidation and generation of free radicals (Benson 1990).

The culture of leaflets from in vitro plants derived from embryonic axes was investigated as an alternative method to achieve multiplication. Two diverse morphogenic responses were displayed by leaf explants according to the growth regulator used. MS medium supplemented with BA alone or in association to NAA induced regeneration through indirect organogenesis both in leaflet segments and whole leaflets. Explants enlarged during the first $5 \mathrm{~d}$ and developed green compact calluses after an additional period of $2 \mathrm{wk}$ of culture. Calluses were formed from the petiole in whole leaves and from the wounded surfaces in leaflet segments. These calluses gave rise to green buds 3 wk after culture initiation and shoots $3-5 \mathrm{~cm}$ high were observed after a total period of $4 \mathrm{wk}$.

Wounding had a significant effect on callogenesis and in the number of shoots produced per explant. Leaflet segments showed high callusing frequencies $(100 \%)$ irre- spective of BA concentration and combination to NAA. On the other hand, whole leaflets showed highest frequencies of callus formation $(100 \%)$ only in response to $30.8 \mu \mathrm{M}$ $\mathrm{BA}$ or to combinations of NAA to $4.4 \mu \mathrm{M}$ BA (Table 1). Better regenerative responses in wounded leaflets when compared to intact explants were also described for other species (D'Onofrio and Morini 2003; Bhagwat and Lane 2004). This may be a reflection of different endogenous hormonal balance and cell differentiation levels in segments from the same organ, leading to distinct sensibility to plant growth regulators (Koroch et al. 2002).

Growth regulators did not play a significant role in the regeneration efficiency from leaf explants of $A$. stenosperma. However, a trend toward a better shoot differentiation was observed when BA was used alone or in association to low NAA concentrations (Table 1). Shoot development was not positively correlated to the frequency of callus formation, as BA concentrations that induced highest callogenesis were not always the most effective for adventitious shoot induction. It is possible that growth regulator concentrations that stimulate cell division to a certain level impair the molecular processes involved in cell differentiation. In addition, the interaction between endogenous auxins and exogenous cytokinins may lead to inhibition of shoot production (Dornelas and Vieira 1994).

Plant regeneration from leaflets of in vitro and greenhouse plants has been achieved in several wild Arachis species in response to associations of cytokinins and auxins (Johnson and Pittman 1986; Dunbar and Pittman 1992; Rey et al. 2000). However, in previous investigations on in vitro regeneration of $A$. stenosperma only callus production was achieved when greenhouse mature leaflets were cultured in the presence of NAA associated to BA (Pittman et al. 1983).

Media supplemented with NAA alone induced rhizogenesis in both explant types in response to the concen-

Figure 2. Rhizogenesis from leaf explant of $A$. stenosperma $\mathrm{V} 14455$ in response to $5.4 \mu \mathrm{M}$ NAA. (a) Root formation from the petiole; $(b)$ roots originated from whole leaf after 8 wk of culture; $(c)$ shoot production from roots after $12 \mathrm{wk}$ of culture. Bar=1 cm.
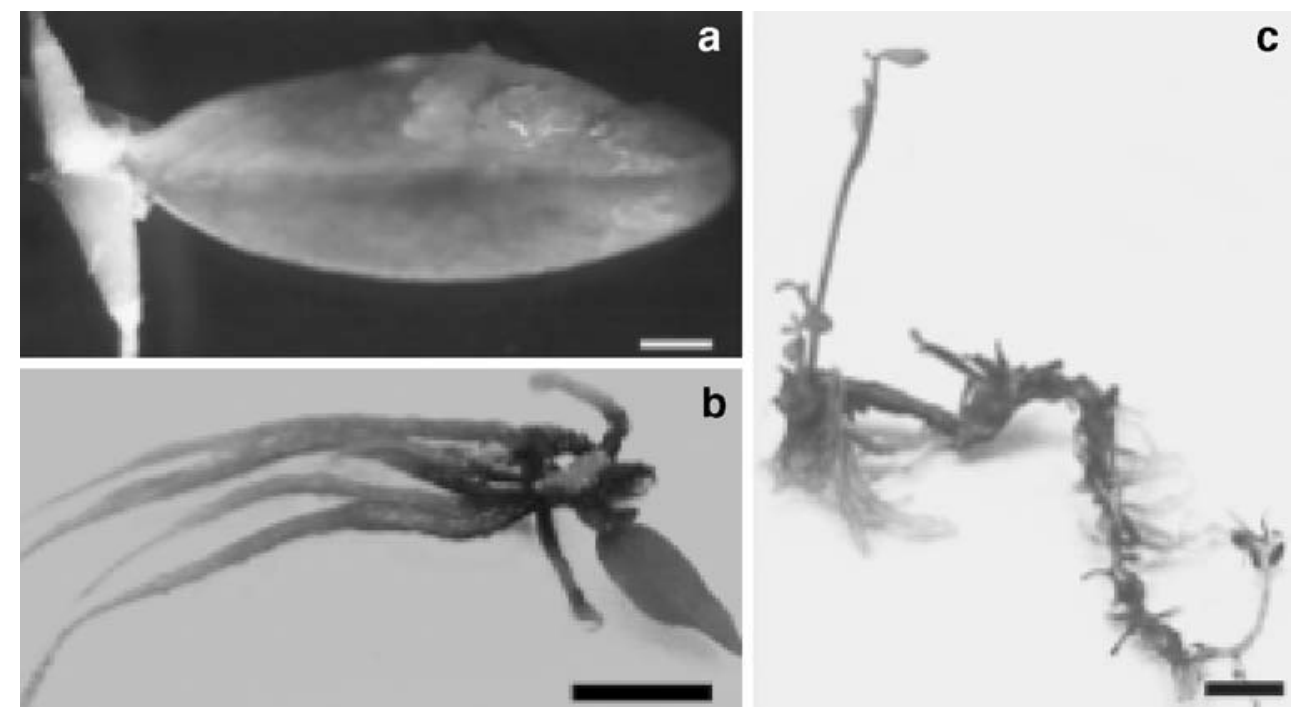
trations tested, except for whole leaflets cultured on $54 \mu \mathrm{M}$ NAA (Fig. 1). Rhizogenesis started from the petioles in both explant types after $4 \mathrm{wk}$ of culture (Fig. 2a-b). Secondary root formation was also observed. Adventitious root formation from leaf explants was previously described for several species in response to auxins (da Gloria et al. 1999; Koroch et al. 2002; Wadegaonkar et al. 2006). The interaction between endogenous and exogenous auxins may stimulate cell division activity and the subsequent development of root meristems, similarly to the formation of lateral roots (Taiz and Zeiger 2004).

After an additional period of $15 \mathrm{~d}$ of culture, shoots $(0.75 \pm 0.5$ shoots per root) were formed directly from the roots produced in response to low levels of NAA (5.4 and $10.8 \mu \mathrm{M}$ ), at frequencies of $10-30 \%$ (Fig. 2c). After the expression of NAA-induced rhizogenesis, both explant types showed callus formation in the petiole. Bud formation from roots is a natural phenomenon observed in some plants, especially under stress conditions. In vitro shoot production from roots can occur spontaneously after long culture periods or be induced by growth regulators, even in those species that do not have this natural ability (Nef-Campa et al. 1996; Hosseini-Nasr and Rashid 2002). In Arachis, shoot differentiation from root tissues has already been observed in field conditions (Krapovickas and Gregory 1994) and it was also described in old in vitro cultures of A. villosulicarpa, in response to combinations of NAA and BA (Pittman et al. 1984).

The results presented here demonstrated the morphogenic potential of leaf explants from in vitro plants of A. stenosperma. Direct rhizogenesis from leaf explants of in vitro plants, with subsequent shoot development from the roots was characterized in Arachis for the first time, resulting in a model system to study these processes. Taking into account that these shoots are formed via direct organogenesis, the utilization of leaf tissues from primary in vitro plants derived from embryonic axes may also be considered as a complementary tool to in vitro preservation and multiplication of Arachis.

Acknowledgments We thank FAPERJ (Fundação de Amparo à Pesquisa Carlos Chagas Filho) for awarding a research fellowship to Georgia Pacheco, and CNPq (Conselho Nacional de Desenvolvimento Científico e Tecnológico) for research fellowships to Elisabeth Mansur and José Francisco Montenegro Valls.

\section{References}

Benson, E.E. Free-radical damage in storage plant germplasm. Rome: International Board for Plant Genetic Resources; 128p; 1990.

Bhagwat, B.; Lane, W.D. In vitro shoot regeneration from leaves of sweet cherry (Prunus avium) "Lapins" and "Sweetheart". Plant Cell Tissue Organ Cult. 78: 173-181; 2004. da Gloria, B.A.; Vieira, M.L.C.; Dornelas, M.C. Anatomical studies of in vitro organogenesis induced in leaf-derived explants of passionfruit. Pesqui. Agropecu. Bras. 34: 2007-2013; 1999.

D'Onofrio, C.; Morini, S. Simultaneous regeneration of different morphogenic structures from quince leaves as affected by growth regulator combination and treatment length. Biol. Plant. 47: 321$325 ; 2003$.

Dornelas, M.C.; Vieira, M.L.C. Tissue culture studies on species of Passiflora. Plant Cell Tissue Organ Cult. 36: 211-217; 1994.

Dunbar, K.B.; Pittman, R.N. Adventitious shoot formation from mature leaf explants of Arachis species. Crop Sci. 32: 1353-1356; 1992.

Dunbar, K.B.; Pittman, R.N.; Morris, J.B. In vitro culture of embryonic axes from Arachis species for germplasm recovery. J. Seed Technol. 17: 1-8; 1993.

Gagliardi, R.F.; Pacheco, G.P.; Coculilo, S.P.; Valls, J.F.M.; Mansur, E. In vitro plant regeneration from seed explants of wild groundnut species (Genus Arachis, Section Extranervosae). Biodivers. Conserv. 9: 943-951; 2000.

Grosso, N. R.; Nepote, V.; Guzman, C.A. Chemical composition of some wild peanut species (Arachis) seeds. J. Agric. Food Chem. 48: 806-809; 2000.

Hosseini-Nasr, M.; Rashid A. Thidiazuron-induced shoot-bud formation on root segments of Albizzia julibrissin is an apexcontrolled, light-independent and calcium-mediated response. Plant Growth Regul. 36: 81-85; 2002.

Johnson, B.B.; Pittman, R.N. Factors affecting in vitro differentiation of explants from mature leaves of Arachis villosulicarpa Hoehne. In Vitro Cell. Dev. Biol. Plant 22: 713-715; 1986.

Koroch, A.; Juliani, H. R.; Kapteyn, J.; Simon, J. E. In vitro regeneration of Echinacea purpurea from leaf explants. Plant Cell Tissue Organ Cult. 69: 79-83; 2002.

Krapovickas, A.; Gregory, W.C. Taxonomy of genus Arachis (Leguminosae). Bonplandia 8: 1-186; 1994.

Morris, J.B.; Dunn, S.; Pittman, R.N. Plant recovery from embryonic axes of deteriorated peanut seed for germplasm renewal. Peanut Sci. 22: 66-70; 1995.

Murashige, T.; Skoog, F. A revised medium for rapid growth and bioassays with tobacco tissue culture. Physiol. Plant. 15: 473479; 1962.

Nef-Campa, C.; Chaintreuil-Dongmo, C.; Dreyfus, B.L. Regeneration of the tropical legume Aeschynomene sensitiva Sw. from root explants. Plant Cell Tissue Organ Cult. 44: 149-154; 1996.

Pacheco, G.; Gagliardi, R.F.; Carneiro, L.A.; Valls, J.F.M.; Mansur, E. In vitro regeneration and conservation of wild species of Arachis. J. Hortic. Sci. Biotechnol. 82: 311-315; 2007.

Pittman, R.N.; Banks, D.J.; Kirby, J.S.; Mitchell, E.D.; Richardson, P.E. In vitro culture of immature peanut (Arachis spp.) leaves: Morphogenesis and plantlet regeneration. Peanut Sci. 10: 21-25; 1983.

Pittman, R.N.; Johnson, B.B.; Banks, D.J. In vitro differentiation of a wild peanut, Arachis villosulicarpa Hoehne. Peanut Sci. 11: 2427; 1984.

Rey, H.Y.; Scocchi, A.M.; Gonzalez, A.M.; Mroginski, L.A. Plant regeneration in Arachis pintoi (Leguminosae) through leaf culture. Plant Cell Rep. 19: 856-862; 2000.

Sharma, S.B.; Ansari, M.A.; Varaprasad, K.S.; Singh, A.K.; Reddy, L. J. Resistance to Meloidogyne javanica in wild Arachis species. Genet. Resour. Crop Evol. 46: 557-568; 1999.

Subrahmanyam, P.; Naidu, R.A.; Reddy, L.J.; Kumar, P.L.; Fergurson, M.E. Resistance to groundnut rosette disease in wild Arachis species. Appl. Biol. 139: 45-50; 2001.

Taiz, L.; Zeiger, E. Auxins. In: Plant Physiology. Massachusetts: Sinauer Associates Inc.; 2004: 543-589.

Wadegaonkar, P.A.; Bhagwat, K.A.; Rai, M.K. Direct rhizogenesis and establishment of fast growing normal root organ cuture of Withania somnifera Dunal. Plant Cell Tissue Organ Cult. 84: 223-225; 2006. 